\title{
Peak systolic velocity using color-coded tissue Doppler imaging, a strong and independent predictor of outcome in acute coronary syndrome patients
}

Carl Westholm ${ }^{1,2^{*}}$, Jonas Johnson ${ }^{3}$, Anders Sahlen ${ }^{1,2}$, Reidar Winter ${ }^{1,2,3}$ and Tomas Jernberg ${ }^{1,2}$

\begin{abstract}
Background: Traditional echocardiographic methods like left ventricular ejection fraction(EF) and wall motion scoring (WMS) and new methods like speckle tracking (ST) based 2D strain carry important prognostic information in acute coronary syndrome (ACS) patients. Parameters from tissue Doppler imaging (TDI), with its high time resolution, may further increase the prognostic value. Peak systolic velocity (PSV) of the basal segments of the left ventricle from TDI is a robust and user independent parameter. The aim was to investigate the prognostic value of PSV compared to EF, WMS, 2D strain and E/e'.
\end{abstract}

Methods: Echocardiographic images were collected and post processed in 227 ACS patients. Additional clinical data was prospectively gathered and patients were followed for 3-5 years regarding the combined endpoint of death or re-admission due to ACS or heart failure.

Results: The combined endpoint occurred in 85 (37\%) patients. Those with an event had lower median PSV than those without $(4,4 \mathrm{~cm} / \mathrm{s})$ vs. $(5,3 \mathrm{~cm} / \mathrm{s}),(p<0.001)$. In a ROC analysis, the AUC was larger for PSV $(0.75)$ than for EF (0.68), WMS (0.63), 2D strain (0.67) and E/e'(0.70). The combined endpoint increased with decreasing PSV. When adjusting for differences in baseline characteristics in a COX-regression model, PSV remained independently associated with outcome where the others did not. PSV was also less sensitive to image quality with fewer values missing or unacceptable for analysis.

Conclusion: Peak systolic velocity (PSV) is a robust measurement that seems to have a strong and independent association with outcome compared to traditional echocardiographic measurements in ACS patients.

Keywords: Acute coronary syndrome, Prognostic parameters, Tissue Doppler, Peak systolic velocity

\section{Background}

Patients admitted to hospital because of an acute coronary syndrome (ACS) constitute a heterogeneous population with a varying risk of future cardiac events. To identify high-risk patients who may benefit from an intensified treatment strategy and low-risk patients who may benefit from a more conservative approach and early discharge, risk stratification is important. Traditionally,

\footnotetext{
* Correspondence: carl.westholm@karolinska.se

'Department of Medicine, Section of Cardiology, Karolinska Institutet, Stockholm, Sweden

${ }^{2}$ Departement of Cardiology, Karolinska University Hospital, Stockholm, Sweden

Full list of author information is available at the end of the article
}

echocardiographic measurements of left ventricular systolic function, such as ejection fraction (EF) and wall motion scoring (WMS), have been considered as essential in this process [1,2] However both EF and WMS are limited by being highly user dependent with a rather long learning curve and poor reproducibility $[3,4]$. Subsequent studies have introduced the diastolic echocardiographic parameter $\mathrm{E} / \mathrm{e}^{\prime}$-ratio, that reflects the filling pressure of the left ventricle [5] as a prognostic parameter with incremental value to EF and WMS [6,7]. It has also been shown that this parameter adds complementary prognostic value to biochemical markers such as type B natriuretic peptide $[8,9]$ after acute myocardial infarction (AMI) $[10,11]$. 
A more recently developed quantitative parameter like strain obtained from two-dimensional (2D) echocardiography based speckle tracking or tissue doppler imaging (TDI) has also been shown to add prognostic value to the traditional parameters $[12,13]$. This measurement derived from speckle tracking or TDI is less user dependent and more easily accessible compared to $2 \mathrm{D}$-derived EF, WMS and E/e' although problems with feasibility remains [14-17].

Whereas systolic values of parameters like global systolic strain and the diastolic parameter E/e'-ratio have been shown useful for risk stratification in ACS patients, less is known about the prognostic value of systolic tissue velocities in this group of patients.

Peak systolic velocity (PSV) of the basal segments of the left ventricle from TDI is a feasible and relatively user independent measure (Figure 1). Tissue Doppler imaging has a higher time resolution than 2D-speckle tracking echocardiography and can therefore register processes not visible for the human eye or for speckle tracking $[18,19]$. The aim of this study was to investigate the prognostic value and feasibility of PSV compared to both traditional parameters, such as EF, WMS, E/e'-ratio and more recent such as 2D-strain.

\section{Method}

\section{Study population}

The study included patients admitted to the coronary care unit at Karolinska University Hospital, Huddinge, between August 2006 and January 2008 with a clinical diagnosis of ACS including unstable angina pectoris, ST elevation myocardial infarction and non ST elevation myocardial infarction. The patients were consecutively included except for temporary interruptions of the study due to high work load at the coronary care unit. Cardiac comorbidities such as valvular disease or arrhythmia were not reasons for exclusion. All patients underwent clinical assessment including clinical history, physical examination, standard 12-lead ECG, ECG-monitoring and serial measurement of biochemical cardiac markers up to 9-12 hours after admission. All other examinations and treatments were left to the discretion of the individual cardiologist. Clinical data were prospectively collected and entered into a database. An acute MI was defined according to current guidelines [20].

The combined end point was death from any cause, MI and rehospitalisation for heart failure. All in-hospital events were registered in the study database. Only new MIs occurring more than 24 hours after admission were considered as events. Out of hospital, information about death and need for readmission because of MI or heart failure was obtained by merging the database with the National Death Registry, which includes information of the vital status of all Swedish citizens, and the National Patient Registry, which includes diagnoses on all patients hospitalized in Sweden.

All patients received oral and written information about the study and written informed consent was obtained

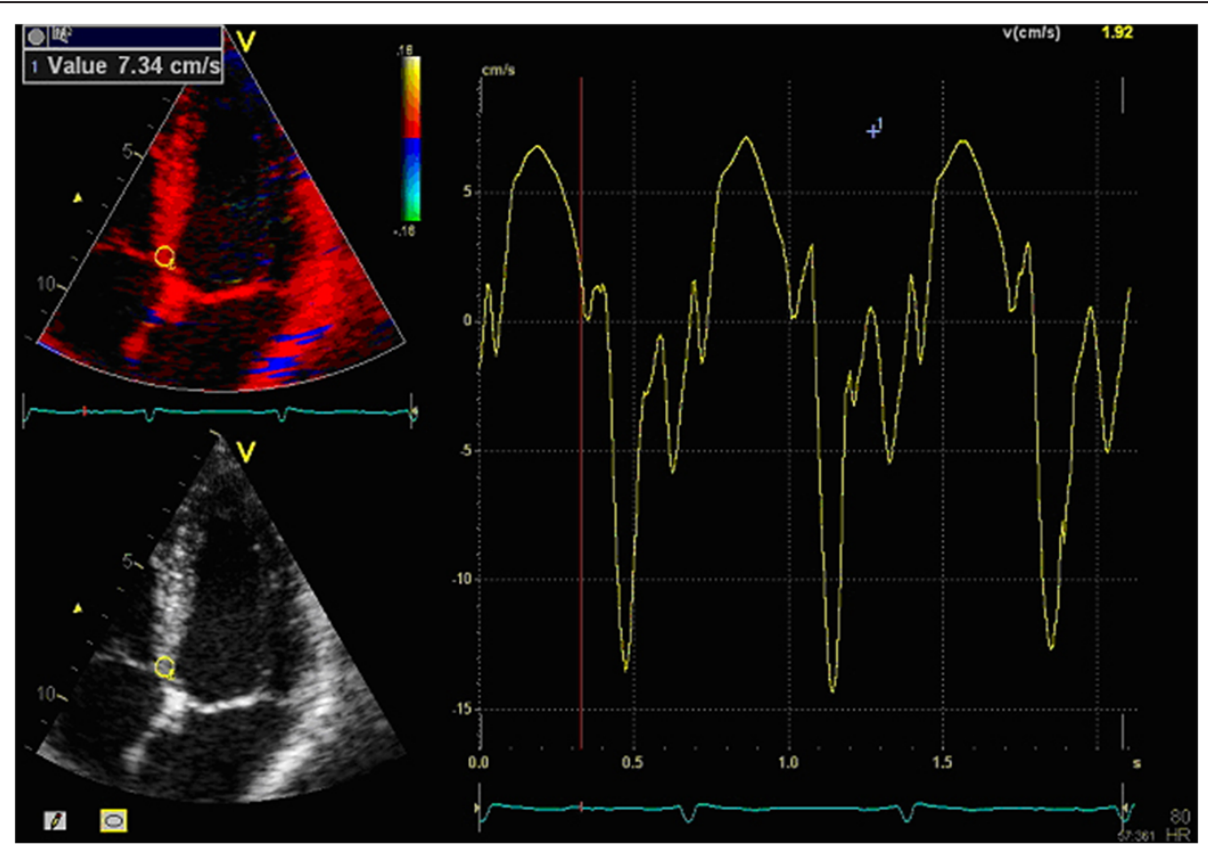

Figure 1 How the peak systolic velocity (PSV) information is acquired. The region of interest (ROI) is manually placed in the basal segments of the left ventricle and the corresponding tissue velocity is showed in the graph to the right where you can register the PSV guided by the ECG below in the picture. The time is on the $x$-axis and velocity in $\mathrm{cm} / \mathrm{s}$ on the $y$-axis. 
before entering the study. The study was conducted according to the principles of the Declaration of Helsinki and was approved by the local ethics committee.

\section{Laboratory analyses}

$\mathrm{N}$-terminal pro B-type natriuretic peptide (NT-proBNP) was determined 24 hours after admission by using the assay from Roche Diagnostics on a Modular Analytics E170. The analytical range extends from 20 to $35000 \mathrm{ng} / \mathrm{L}$. Plasma creatinine was analysed on admission. Estimated glomerular filtration rate (eGFR) was calculated by using the Cockcroft-Gault formula [21].

\section{Echocardiographic acquisition and analyses}

All echocardiography data was collected during the first days (median (25th-75th percentile): 3(2-4)) of admission according to the local standard clinical protocol at that time on Karolinska University Hospital by the cardiologist or cardiac technician on duty that day. The images, including 2D, TDI and spectral Doppler, were collected with a GE Vingmed vivid7 ultrasound machine with a M3S or M4S transducer and standard installed software.

The images were analyzed using a dedicated workstation (EchoPAC, GE Healthcare, Horten Norway) by a well-trained cardiologist $(\mathrm{CW})$ blinded to baseline data and subsequent outcome.

Ejection fraction was measured according to current EAE/ASE recommendations [22] using the biplane Simpson method of discs from outlining the endocardial border in the apical 4-, and 2-chamber views.

Wall motion score was determined as the mean value of an 18 segment model from the three apical views, where each segment was given a score of $1-3$, in which 1 represented normokinesia, 2 indicated hypokinesia, and 3 , akinesia.

Two dimensional-strain was derived from apical 2D images using the EchoPAC software. Global 2D strain was calculated as the mean of the regional longitudinal strain of the 18 different segments and was calculated if the strain was measurable in at least 12 segments. The Automatic tracking was visually controlled and manually corrected if needed. Strain information can also be obtained from TDI but in this material the apical projections of TDI did often not include the apical segments and quite often also just parts of the midventricular segment and therefore we concluded that Strain from TDI could not be obtained in this study.

$\mathrm{E} / \mathrm{e}^{\prime}$ was calculated from the E-wave of the mitral inflow to the LV measured by pulsed Doppler and e' was measured from the four chamber TDI image as the mean of the septal and lateral maximum diastolic velocities.

PSV was measured from TDI images, as illustrated in Figure 1. The global PSV value was defined as the mean of the velocities from the 6 different basal segments of the left ventricle. We excluded velocity peaks from the isovolumetric phases with end systole defined by the closing of the aortic valve in the three chamber projection. As mentioned above, the images were collected by various sonographers and physicians during the inclusion without standardized frame rate which therefore varied between 100 and 150 frames/s between patients. As the longitudinal velocities are a more global parameter compared to Strain with co variation between adjacent segments we calculated PSV if the basal velocity was measureable in at least 2 of 6 segments. To confirm that assumption the correlation between the PSV only from the septal and lateral wall and that of PSV as mean from all basal segments was examined.

Image quality was registered using a four-grade scale, as well as the reason for a missing value (non existing image or too poor quality to allow analysis).

To investigate the interobserver variability, another well-trained cardiologist (AS) measured PSV on 20 randomly chosen patients. The variability was evaluated by calculating the Coefficient of Variation (CV) using the formula "CV = Standard deviation / expected return" where the expected return is the mean of all the measurements by both readers, and the standard deviation is of the differences between the paired readings. As PSV was our main focus in this study we did not investigate the $\mathrm{CV}$ of other parameters that has already been investigated [16].

\section{Statistical analysis}

Continuous data are presented as medians with interquartile range (IQR) and categorical data are presented with frequencies and percent. When analyzing differences between groups the Mann Whitney-test was used for continuous variables and Chi2-test for categorical variables. To compare the prognostic value regardless of chosen cut off-value, we used receiver operating characteristics (ROC) analyses expressing prognostic value as area under curve (AUC) with 95\% confidence interval (CI) and significance tested according to Hanley and McNeil [23] To illustrate the timing of events, Kaplan Meier curves were generated. Correlations were evaluated with Spearman's rho.

To identify which echocardiographic parameters were independent predictors of outcome we used Coxregression analyses, adjusting for other variable well known to be associated with outcome (age, gender, diabetes, hypertension and previous heart failure) in three different models. In model 1 each tested echocardiographic parameter was entered one by one together with the above mentioned risk factors. In model 2 we also included NT proBNP and eGFR among the risk factors to adjust for. In model 3 we removed NT proBNP and 
Table 1 Baseline characteristics $(n=227)$

\begin{tabular}{|c|c|c|c|c|c|c|c|}
\hline \multirow[b]{2}{*}{ Variables } & \multicolumn{2}{|c|}{$\begin{array}{c}\text { All } \\
(n=227)\end{array}$} & \multicolumn{2}{|c|}{$\begin{array}{l}\text { No death, MI or HF } \\
\qquad(n=142)\end{array}$} & \multicolumn{2}{|c|}{$\begin{array}{l}\text { Death, MI or HF } \\
\quad(n=85)\end{array}$} & \multirow[b]{2}{*}{$\mathrm{p}$} \\
\hline & $\mathbf{n}$ & (\%) & $\mathbf{n}$ & (\%) & $\mathbf{n}$ & $(\%)$ & \\
\hline \multicolumn{8}{|l|}{ Demographics: } \\
\hline Age (median, 25th-75th perc.) & 67 & $(59-77)$ & 62 & $(56-74)$ & 74 & $(63-80)$ & $<0,001$ \\
\hline Men & 172 & (76) & 111 & (78) & 61 & (72) & 0.276 \\
\hline \multicolumn{8}{|l|}{ Risk factors: } \\
\hline Hypertension & 121 & (53) & 63 & (44) & 58 & (68) & $<0.001$ \\
\hline Diabetes Mellitus & 51 & (22) & 29 & (20) & 22 & (26) & 0.340 \\
\hline Current smoker (missing $n=6$ ) & 43 & (19) & 33 & (23) & 10 & (13) & 0.049 \\
\hline \multicolumn{8}{|l|}{ Previous cardiovascular disease: } \\
\hline Myocardial infarction & 56 & (25) & 31 & (22) & 25 & (30) & 0.200 \\
\hline Heart Failure & 19 & (8) & 2 & (1) & 17 & (20) & $<0.001$ \\
\hline Revascularization, $\mathrm{PCl}$ & 33 & (15) & 23 & (16) & 10 & (12) & 0.359 \\
\hline Revascularization, CABG & 10 & (4) & 4 & (3) & 6 & (7) & 0.132 \\
\hline Stroke & 17 & (7) & 10 & (7) & 7 & (8) & 0.741 \\
\hline \multicolumn{8}{|l|}{ Laboratory measurements } \\
\hline NTproBNP $24 \mathrm{~h}$ (median, 25th-75th perc.) $(\mathrm{n}=189))$ & & & 724 & $(303-1887)$ & 2300 & $(1030-26040)$ & $<0.001$ \\
\hline eGFR (median, 25th-75th perc.) $(\mathrm{n}=220)$ & & & 92 & $(72-116)$ & 66 & $(40-96)$ & $<0.001$ \\
\hline \multicolumn{8}{|l|}{ Index Diagnosis } \\
\hline Myocardial infarction & 188 & (83) & 119 & (84) & 69 & (81) & 0.612 \\
\hline
\end{tabular}

$\mathrm{Ml}=$ Myocardial infarction, $\mathrm{HF}=$ Heart failure, eGFR=glomerular filtration rate.

eGFR, and instead inserted PSV among the risk factors to adjust for. To evaluate whether early intervention influenced the association between PSV and outcome, coronary angiography and treatment with PCI or CABG were also included in the models.

\section{Results}

A total of 227 patients were included in the study. The median follow up time was $53(48-58)$ months. During this period $85(37 \%)$ patients reached the combined endpoint, among them 42 (19\%) died, 48 (21\%) had a MI and $52(23 \%)$ were readmitted because of heart failure. Baseline characteristics, laboratory data and final diagnoses at the index event in all patients and in those with and without a subsequent event are listed in Table 1. Patients with an event were older and had more often hypertension and a previous history of heart failure. They also had a higher level of NT-proBNP and a lower eGFR. Coronary angiography was performed in 192 patients, of which 109 and 25 underwent percutaneous coronary intervention (PCI) and coronary bypass surgery (CABG), respectively.

\section{Echocardiographic acquisition and measurements}

Peak systolic velocity could be measured in all except 3 (1\%) patients, whereas EF Simpson and WMS could not be assessed in 19 (8\%) and 9 (4\%) patients, respectively. $2 \mathrm{D}$-strain could not be obtained in 41 (18\%) of the

Table 2 Echocardiographic measurements

\begin{tabular}{|c|c|c|c|c|c|c|c|}
\hline \multirow[b]{2}{*}{ Variables } & \multicolumn{2}{|c|}{$\begin{array}{c}\text { All } \\
(n=227)\end{array}$} & \multicolumn{2}{|c|}{$\begin{array}{l}\text { No death, MI or HF } \\
\qquad(n=142)\end{array}$} & \multicolumn{2}{|c|}{$\begin{array}{c}\text { Death, MI or HF } \\
\quad(n=85)\end{array}$} & \multirow[b]{2}{*}{$p$} \\
\hline & median & (25th-75th perc) & median & (25th-75th perc) & median & (25th-75th perc) & \\
\hline PSV & 4.9 & $(4.2-5.8)$ & 5.3 & $(4.7-6.0)$ & 4.4 & $(3.6-5.0)$ & $<0.001$ \\
\hline EF & 49 & $(41-56)$ & 52 & $(45-58)$ & 45 & $(35-52)$ & $<0.001$ \\
\hline WMS & 1.0 & $(1.0-1.3)$ & 1.26 & $(1.09-1.16)$ & 1.29 & $(1.21-1.36)$ & $<0.001$ \\
\hline Global 2D-Strain & -14 & $(-18--9.8)$ & -15 & $(-19--11)$ & -11 & $(-16.8--5.0)$ & $<0.001$ \\
\hline E/e'-ratio & 13.4 & $(10.1-17.6)$ & 13.2 & $(12.3-14.2)$ & 18.4 & $(16.1-20.8)$ & $<0.001$ \\
\hline
\end{tabular}

$\mathrm{Ml}=$ Myocardial infarction, $\mathrm{HF}=$ Heart failure, $\mathrm{PSV}=$ peak systolic velocity, $\mathrm{EF}=$ ejection fraction, $\mathrm{WMS}=$ Wall motion scoring. 
Table 3 Area under curve according to ROC-analysis

\begin{tabular}{ll}
\hline Variables & AUC (95\%Cl) \\
\hline PSV & $0.75(0.68-0.81)$ \\
EF & $0.68(0.61-0.76)$ \\
WMS & $0.64(0.56-0.72)$ \\
Global 2D-Strain & $0.67(0.58-0.75)$ \\
E/e'-ratio & $0.70(0.62-0.77)$ \\
\hline
\end{tabular}

patients and the corresponding number for E/e' was 28 (12\%). The results of the echocardiographic measurements are listed in Table 2. When assessing the interobserver variability between two observers regarding PSV measurements the CV was $5.9 \%$. The correlation (Spearman's rho) between global PSV calculated from 6 basal segments and PSV calculated from only the septal and lateral segment was 0.91 .

\section{Prognostic value of peak systolic velocity in comparison} to other echocardiographic data

Patients with an combined event had lower median PSV than those without $(4,4 \mathrm{~cm} / \mathrm{s})$ vs. $(5,3 \mathrm{~cm} / \mathrm{s}),(\mathrm{p}<0.001)$. These groups also differed significantly regarding $\mathrm{EF}$ Simpson, WMS, strain and E/e'-ratio (Table 2). In ROC analyses, the AUC (Area under curve) was larger for
PSV than for the other parameters but the differences did not reach statistical significance (Table 3). When patients were divided into tertiles according to the PSV measurements the long term risk of subsequent cardiac events increased with decreasing PSV (Figure 2). The association between PSV and outcome was apparent for all individual endpoints (Table 4).

\section{Independent predictors of outcome}

All tested echocardiographic parameters except 2Dstrain remained independently associated with outcome when these variables one at the time were adjusted for age, gender, diabetes, hypertension and previous heart failure (Table 5, model 1). When patients in the third tertile according to PSV $(>5.5 \mathrm{~cm} / \mathrm{s})$ were used as reference the $\mathrm{HR}(95 \% \mathrm{CI})$ increased to $1.65(0.80-3.37)$ $\mathrm{p}=0.169$, and $3.16(1.58-6.35) \mathrm{p}=0.001$ in the second and first tertile, respectively. In model 2 where NT-proBNP and eGFR were added to the model, only PSV, and E/e' and remained independent predictors of outcome (Table 5, model 2). When including PSV in the model, PSV was the only echocardiographic parameter independently associated with outcome (Table 5 , model 3 ).

When we included intervention with PCI or CABG in the model, PSV remained significantly associated with outcome, $(\mathrm{HR}(95 \%) 0.66(0.51-0,84), \mathrm{p}=0.001)$.

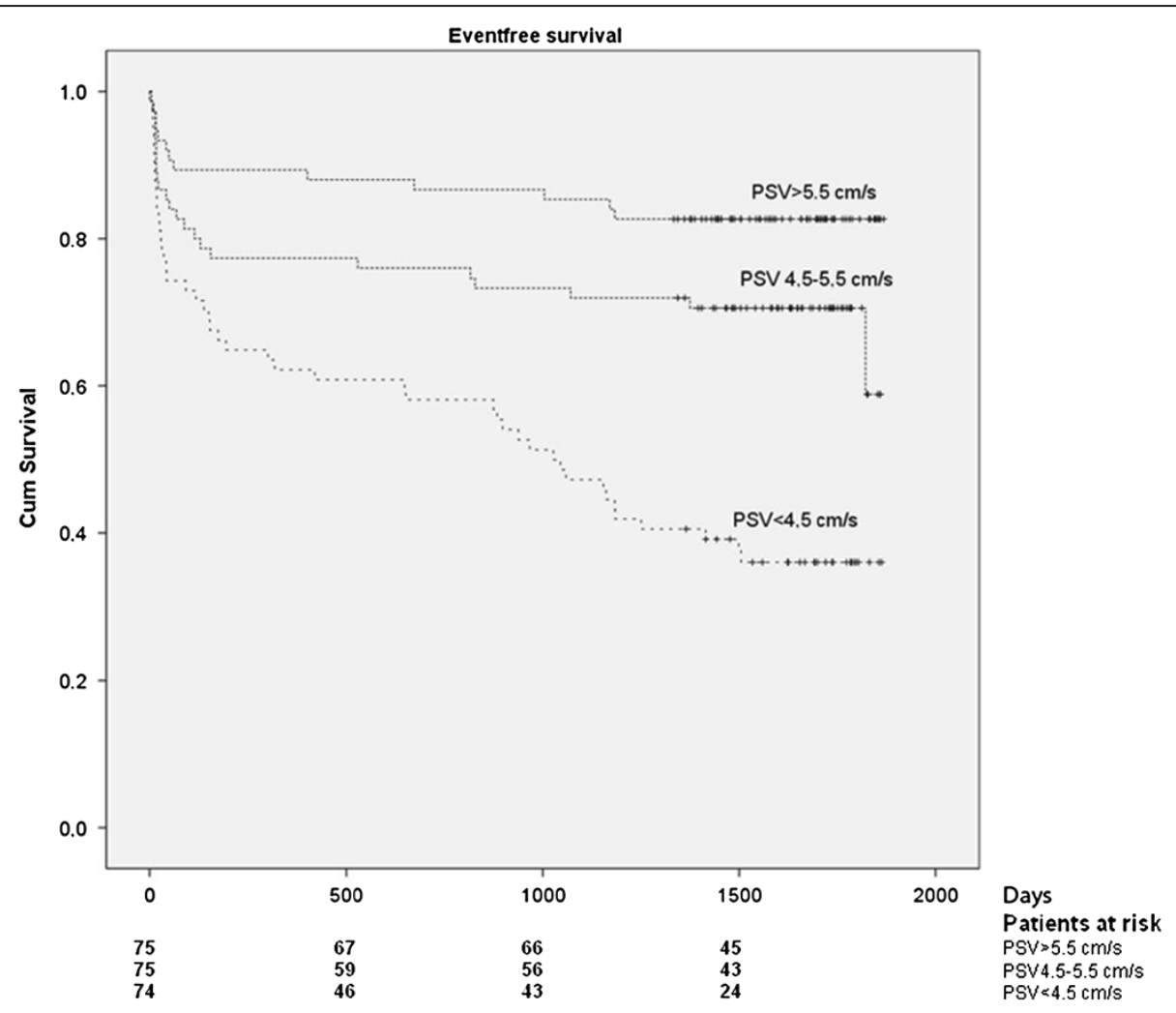

Figure 2 Combined endpoint (death, myocardial infarction or readmission because of heart failure) in relation to PSV measurement. 
Table 4 Events according to different PSV:s

\begin{tabular}{llll}
\hline & $\begin{array}{l}\text { PSV }<\mathbf{4 . 5} \\
\mathbf{c m} / \mathbf{s}\end{array}$ & $\begin{array}{l}\text { PSV 4.5-5.5 } \\
\mathbf{c m} / \mathbf{s}\end{array}$ & $\begin{array}{l}\text { PSV }>\mathbf{5 . 5} \\
\mathbf{c m} / \mathbf{s}\end{array}$ \\
\hline $\begin{array}{l}\text { Death } \\
\text { Re-admission due } \\
\text { to heart failure }\end{array}$ & 26 & 12 & 4 \\
$\begin{array}{l}\text { New Ml } \\
\text { Combined endpoint }\end{array}$ & 42 & 15 & 4 \\
(all the above) & 26 & 14 & 8 \\
\hline
\end{tabular}

\section{Discussion}

This study demonstrates that PSV can be measured in most patients with a low interobserver variability and may even be a better predictor of outcome than both traditional echocardiographic measurements of left ventricular function, such as EF, WMS and E/e'-ratio and more recent deformation parameters, such as myocardial strain in ACS patients.

The aim of this study was to test PSV in a real world setting. We therefore included consecutive unselected ACS patients and all images were acquired as in the clinical routine. In the univariable analyses, the median PSV value was lower in those with than in those without a subsequent cardiac event. When categorizing patients according PSV values, a low-, intermediate- and highrisk group could be identified with a 5-year cumulative risk of death, MI or readmission because of heart failure of $17 \%, 32 \%$ and $64 \%$, respectively. Even after adjusting for differences in well-known predictors of outcome (including natriuretic peptides and estimates of kidney function), there was a strong association between PSV and outcome, with a 1.4 fold increased risk of the combined endpoint for every unit decrease in PSV.
When the prognostic value of PSV was compared with that of other echocardiographic parameters in a ROC analysis, PSV had the largest AUC although the differences were not statistical significant. When the echocardiographic parameters were tested one by one in a regression model including well-known predictor of outcome, only PSV and E/e'-ratio remained associated with outcome, whereas EF, WMS and strain failed to independently predict outcome. Finally, when PSV was included in the model, none of the other echocardiographic parameters carried any additional prognostic information.

The predictive value of different echocardiographic parameters may vary in different patient populations. Wang et al. [6] demonstrated a better prognostic value for both é, PSV and E/e' than for EF and WMS. In that study e' was the strongest predictor of cardiac death although PSV and E/e' also were strong predictors of cardiac death. However, the study by Wang and co-workers included patients with a broad spectrum of heart disease and only $16 \%$ had ischemic heart disease. The fact that the diastolic parameter e' was demonstrated to have a higher prognostic value than PSV might be explained by a relatively small proportion of patients having ischemic heart disease and a larger proportion of patients having heart failure. In such a population the proportion of patients with high filling pressure is expected to be higher than in our study population, which included ACS patients with predominantly normal or only mildly depressed EF.

Our study does not only confirm but also extends previous findings showing that $\mathrm{E} / \mathrm{e}^{\prime}$ has an incremental prognostic value to that of natriuretic peptides $[8,9]$. Somewhat unexpectedly $2 \mathrm{D}$-strain was not better to predict outcome than traditional measurements of systolic

Table 5 Cox-regression analysis

\begin{tabular}{|c|c|c|c|c|c|c|}
\hline \multirow[t]{3}{*}{ Parameter } & \multirow{2}{*}{\multicolumn{2}{|c|}{$\begin{array}{l}\text { Model } 1 . \\
\text { Adjusted for age, gender, } \\
\text { diabetes, hypertension and } \\
\text { previous heart failure. }\end{array}$}} & \multirow{2}{*}{\multicolumn{2}{|c|}{$\begin{array}{l}\text { Model } 2 . \\
\text { Adjusted for the same factors } \\
\text { as model } 1 \text { plus NT proBNP } \\
24 \mathrm{~h} \text { and eGFR }\end{array}$}} & \multirow{2}{*}{\multicolumn{2}{|c|}{$\begin{array}{l}\text { Model } 3 . \\
\text { Adjusted for the same as model } 1 \\
\text { plus PSV. The corresponding } \\
\text { results for PSV is also presented } \\
\text { for each parameter HR }(95 \% \mathrm{Cl})\end{array}$}} \\
\hline & & & & & & \\
\hline & HR $(95 \% \mathrm{Cl})$ & $p$ & HR $(95 \% \mathrm{Cl})$ & $\mathrm{p}$ & $\mathrm{HR}(95 \% \mathrm{Cl})$ & $\mathrm{p}$ \\
\hline PSV & $0.65(0.51-0.82)$ & $<0.001$ & $0.71(0.54-0.93)$ & 0.013 & -———-—-— & \\
\hline \multirow[t]{2}{*}{ EF } & $0.97(0.95-0.99)$ & 0.006 & $0.98(0.96-1.00)$ & 0.070 & $0.99(0.96-1.01)$ & 0.227 \\
\hline & & & & & PSV $0.68(0.52-0.90)$ & 0.007 \\
\hline \multirow[t]{2}{*}{ WMS } & $2.09(1.06-4.15)$ & 0.035 & $1.52(0.71-3.24)$ & 0.280 & $0.95(0.41-2.22)$ & 0.915 \\
\hline & & & & & PSV $0.61(0.46-0.82)$ & 0.001 \\
\hline \multirow[t]{2}{*}{ Global 2D Strain } & $1.03(0.99-1.07)$ & 0.003 & $1.04(0.96-1.05)$ & 0.037 & $1.02(0.98-1.06)$ & 0.249 \\
\hline & & & & & PSV $0.67(0.50-0.90)$ & 0.032 \\
\hline \multirow[t]{2}{*}{$E / e^{\prime}$} & $17.97(2.24-144.01)$ & 0.007 & $20.0(2.31-174.4)$ & 0.007 & $6.90(0.740-64.27)$ & 0.090 \\
\hline & & & & & PSV $0.70(0.54-0.91)$ & 0.008 \\
\hline
\end{tabular}


LV function such as EF and WMS. This is in contrast to earlier studies in the field. In a cohort of 649 ACS patients Antoni and co-workers showed that both strain and strain rate were superior to the traditional parameters, EF and WMS, to predict 1-year outcome [16] and similar finding were made by Bertoni and co-workers but in a population with chronic ischemic heart disease [24]. In our study, we could not confirm a superiority of deformation parameters in comparison to EF and WMS. Clearly, the operator's skills and experience, and their compliance to strict protocols are important determinants of the quality of echocardiographic examinations. It is important to note that the images in our study was collected from routine clinical echocardiography not always of highest quality, but still sufficient for analyzing PSV in a very large proportion of the patients, whereas in the study of Antoni et al. and Bertoni et al., all exams were performed within a dedicated laboratory with great experience of conducting studies and using deformation analysis. Still, even if a technique is good in the hands of experts in specialized centers, it can be problematic in the more generalized everyday clinical situation if the demand for technical skill is too high [25].

Therefore, the simplicity of PSV must be regarded as a great advantage, which can be an important determinant to why PSV in our study is superior to the other parameters. Another advantage is the fact that the method seems robust and insensitive to poor image quality with a low interobserver variability and low number of missing values. Thus the results of this study indicates that PSV could be superior to other parameters as a clinical routine method outside a core laboratory to predict outcome. Furthermore the strong correlation (0.91) between global PSV from all 6 basal segments and PSV from only septal and lateral wall indicates that the use of only one projection and two measurement might be as predictive as the global PSV which would further simplifiy the method.

The present study has some limitations. The sample size was rather small. Thus, lack of significant differences may still be caused by lack of power to detect such differences and our findings need to be confirmed in larger studies. Although interobserver variability was assessed for PSV in a subgroup of patients and all analyses were performed according to a protocol, only one person performed the echocardiographic analyses. Due to the clinical setting and image quality, strain rate was not included in this study. Strain rate is the derivate of strain and therefore it is reasonable to believe that the variability and number of missing values would be even higher compared to strain.

This study used a prespecified combined endpoint. Although PSV was significantly associated with all individual endpoints, the underlying mechanisms for these associations may differ. Systolic LV-dysfunction is known to cause both heart failure and death, whereas the association between systolic LV-dysfunction and subsequent risk of new MI may be explained by the association between systolic LV-dysfunction and severity of coronary artery disease.

In conclusion, PSV seems to be a robust and easily obtained echocardiographic measurement that may be very useful for risk stratifying ACS patients.

\section{Competing interests}

The authors declare that they have no competing interests.

\section{Authors' contributions}

All authors read and approved the final manuscript.

\section{Acknowledgement}

We are indebted to the staff at the CCU at Karolinska University Hospital, Huddinge and Margareta Berglund (RN) for all assistance. Financial support was provided through a regional agreement on medical training and clinical research (ALF) between Stockholm County Council and Karolinska Institute. This study was also supported by grants from the Swedish Heart and Lung Foundation and the National Board of Health and Welfare.

\section{Author details}

${ }^{1}$ Department of Medicine, Section of Cardiology, Karolinska Institutet, Stockholm, Sweden. ${ }^{2}$ Departement of Cardiology, Karolinska University Hospital, Stockholm, Sweden. ${ }^{3}$ School of Technology and Health, Royal Institute of Technology, Stockholm, Sweden.

Received: 26 January 2013 Accepted: 27 March 2013

Published: 1 April 2013

\section{References}

1. Moller JE, Hillis GS, Oh JK, Reeder GS, Gersh BJ, Pellikka PA: Wall motion score index and ejection fraction for risk stratification after acute myocardial infarction. Am Heart J 2006, 151(2):419-425.

2. Burns RJ, Gibbons RJ, Yi Q, Roberts RS, Miller TD, Schaer GL, Anderson JL, Yusuf S: The relationships of left ventricular ejection fraction, end-systolic volume index and infarct size to six-month mortality after hospital discharge following myocardial infarction treated by thrombolysis. J Am Coll Cardiol 2002, 39(1):30-36.

3. Jenkins C, Bricknell K, Hanekom L, Marwick TH: Reproducibility and accuracy of echocardiographic measurements of left ventricular parameters using real-time three-dimensional echocardiography. J Am Coll Cardiol 2004, 44(4):878-886.

4. Burianova L, Riedlbauchova L, Lefflerova K, Marek T, Lupinek P, Kautznerova D, Vedlich D, Lanska V, Kautzner J: Assessment of left ventricular function in non-dilated and dilated hearts: comparison of contrast-enhanced 2-dimensional echocardiography with multi-detector row CT angiography. Acta Cardiol 2009, 64(6):787-794.

5. Ommen SR, Nishimura RA, Appleton CP, Miller FA, Oh JK, Redfield MM, Tajik AJ: Clinical utility of Doppler echocardiography and tissue Doppler imaging in the estimation of left ventricular filling pressures: A comparative simultaneous Doppler-catheterization study. Circulation 2000, 102(15):1788-1794.

6. Wang M, Yip GW, Wang AY, Zhang Y, Ho PY, Tse MK, Lam PK, Sanderson JE: Peak early diastolic mitral annulus velocity by tissue Doppler imaging adds independent and incremental prognostic value. J Am Coll Cardiol 2003, 41(5):820-826.

7. Hillis GS, Moller JE, Pellikka PA, Gersh BJ, Wright RS, Ommen SR, Reeder GS, Oh JK: Noninvasive estimation of left ventricular filling pressure by $E / e^{\prime}$ is a powerful predictor of survival after acute myocardial infarction. $J$ Am Coll Cardiol 2004, 43(3):360-367.

8. Morrow DA, de Lemos JA, Sabatine MS, Murphy SA, Demopoulos LA, DiBattiste PM, McCabe CH, Gibson CM, Cannon CP, Braunwald E: Evaluation of B-type natriuretic peptide for risk assessment in unstable angina/nonST-elevation myocardial infarction: B-type natriuretic peptide and prognosis in TACTICS-TIMI 18. J Am Coll Cardiol 2003, 41(8):1264-1272. 
9. Lorgis L, Zeller M, Dentan G, Sicard P, Buffet P, L'Huillier I, Beer JC, VincentMartin M, Makki H, Gambert P, et al: Prognostic value of N-terminal probrain natriuretic peptide in elderly people with acute myocardial infarction: prospective observational study. BMJ 2009, 338:b1605.

10. Kruszewski K, Scott AE, Barclay JL, Small GR, Croal BL, Moller JE, Oh JK, Hillis GS: Noninvasive assessment of left ventricular filling pressure after acute myocardial infarction: a prospective study of the relative prognostic utility of clinical assessment, echocardiography, and B-type natriuretic peptide. Am Heart J 2010, 159(1):47-54.

11. Jernberg $T$, James $S$, Lindahl $B$, Johnston $N$, Stridsberg $M$, Venge $P$, Wallentin L: Natriuretic peptides in unstable coronary artery disease. Eur Heart J 2004, 25(17):1486-1493.

12. Sjoli B, Grenne B, Smiseth OA, Edvardsen T, Brunvand $\mathrm{H}$ : The advantage of global strain compared to left ventricular ejection fraction to predict outcome after acute myocardial infarction. Echocardiography 2011, 28(5):556-563.

13. Antoni ML, Mollema SA, Delgado V, Atary JZ, Borleffs CJ, Boersma E, Holman ER, van der Wall EE, Schalij MJ, Bax JJ: Prognostic importance of strain and strain rate after acute myocardial infarction. Eur Heart J 2010, 31(13):1640-1647.

14. Dandel M, Lehmkuhl H, Knosalla C, Suramelashvili N, Hetzer R: Strain and strain rate imaging by echocardiography - basic concepts and clinical applicability. Curr Cardiol Rev 2009, 5(2):133-148.

15. Leung DY, Ng AC: Emerging clinical role of strain imaging in echocardiography. Heart Lung Circ 2010, 19(3):161-174.

16. Stanton T, Leano R, Marwick TH: Prediction of all-cause mortality from global longitudinal speckle strain: comparison with ejection fraction and wall motion scoring. Circ Cardiovasc Imaging 2009, 2(5):356-364.

17. Hung $C L$, Verma $A$, Uno $H$, Shin $S H$, Bourgoun M, Hassanein AH, McMurray JJ, Velazquez EJ, Kober L, Pfeffer MA, et al: Longitudinal and circumferential strain rate, left ventricular remodeling, and prognosis after myocardial infarction. J Am Coll Cardiol 2010, 56(22):1812-1822.

18. Alam M, Witt N, Nordlander R, Samad BA: Detection of abnormal left ventricular function by Doppler tissue imaging in patients with a first myocardial infarction and showing normal function assessed by conventional echocardiography. Eur J Echocardiogr 2007, 8(1):37-41.

19. van der Hulst AE, Delgado V, Ten Harkel AD, Klitsie LM, Filippini LH, Bax JJ, Blom NA, Roest AA: Tissue Doppler imaging in the left ventricle and right ventricle in healthy children: normal age-related peak systolic velocities, timings, and time differences. Eur J Echocardiogr 2011, 12(12):953-960.

20. Alpert JS, Thygesen K, Antman E, Bassand JP: Myocardial infarction redefined--a consensus document of The Joint European Society of Cardiology/American College of Cardiology Committee for the redefinition of myocardial infarction. Eur Heart J 2000, 21(18):1502-1513.

21. Cockcroft DW, Gault MH: Prediction of creatinine clearance from serum creatinine. Nephron 1976, 16(1):31-41.

22. Lang RM, Bierig M, Devereux RB, Flachskampf FA, Foster E, Pellikka PA, Picard MH, Roman MJ, Seward J, Shanewise J, et al: Recommendations for chamber quantification. Eur J Echocardiogr 2006, 7(2):79-108.

23. Hanley JA, McNeil BJ: The meaning and use of the area under a receiver operating characteristic (ROC) curve. Radiology 1982, 143(1):29-36.

24. Bertini $M, N g$ AC, Antoni ML, Nucifora G, Ewe SH, Auger D, Marsan NA, Schalij MJ, Bax JJ, Delgado V: Global longitudinal strain predicts long-term survival in patients with chronic ischemic cardiomyopathy. Circ Cardiovasc Imaging 2012, 5(3):383-391.

25. Chung ES, Leon AR, Tavazzi L, Sun JP, Nihoyannopoulos P, Merlino J, Abraham WT, Ghio S, Leclercq C, Bax JJ, et al: Results of the Predictors of Response to CRT (PROSPECT) trial. Circulation 2008, 117(20):2608-2616.

doi:10.1186/1476-7120-11-9

Cite this article as: Westholm et al:: Peak systolic velocity using colorcoded tissue Doppler imaging, a strong and independent predictor of outcome in acute coronary syndrome patients. Cardiovascular Ultrasound 2013 11:9.

\section{Submit your next manuscript to BioMed Central and take full advantage of:}

- Convenient online submission

- Thorough peer review

- No space constraints or color figure charges

- Immediate publication on acceptance

- Inclusion in PubMed, CAS, Scopus and Google Scholar

- Research which is freely available for redistribution 